Article

\title{
Numerical Simulation Analysis of Switching Characteristics in the Source-Trench MOSFET's
}

\author{
Jinhee Cheon $\mathbb{D}$ and Kwangsoo Kim * \\ Department of Electronic Engineering, Sogang University, Seoul 04107, Korea; tofawk@naver.com \\ * Correspondence: kimks@sogang.ac.kr; Tel.: +82-2-705-8913
}

Received: 12 October 2020; Accepted: 5 November 2020; Published: 11 November 2020

\begin{abstract}
In this paper, we compare the static and switching characteristics of the $4 \mathrm{H}-\mathrm{SiC}$ conventional UMOSFET (C-UMOSFET), double trench MOSFET (DT-MOSFET) and source trench MOSFET (ST-MOSFET) through TCAD simulation. In particular, the effect of the trenched source region and the gate trench bottom $\mathrm{P}+$ shielding region on the capacitance is analyzed, and the dynamic characteristics of the three structures are compared. The input capacitance is almost identical in all three structures. On the other hand, the reverse transfer capacitance of DT-MOSFET and ST-MOSFET is reduced by $44 \%$ and $24 \%$, respectively, compared to C-UMOSFET. Since the reverse transfer capacitance of DT-MOSFET and ST-MOSFET is superior to that of C-UMOSFET, it improves high frequency figure of merit (HF-FOM: $R_{O N-S P} \times Q_{G D}$ ). The HF-FOM of DT-MOSFET and ST-MOSFET is $289 \mathrm{~m} \Omega \cdot \mathrm{nC}, 224 \mathrm{~m} \Omega \cdot \mathrm{nC}$, respectively, which is improved by $26 \%$ and $42 \%$ compared to C-UMOSFET. The switching speed of DT-MOSFET and ST-MOSFET are maintained at the same level as the C-UMOSFET. The switching energy loss and power loss of the DT-MOSFET and ST-MOSFET are slightly improved compared to C-UMOSFET.
\end{abstract}

Keywords: 4H-SiC; double trench; energy loss; reverse transfer capacitance; source trench; switching

\section{Introduction}

$4 \mathrm{H}-\mathrm{SiC}$ MOSFETs are widely considered to be the leading next-generation power semiconductor devices due to their superior material properties, such as high critical electric field, high thermal conductivity, and ability to operate at high temperatures [1,2]. Of the various $\mathrm{SiC}$ MOSFET structures, gate-trench MOSFETs (UMOSFETs) typically have lower on-state resistance compared to planar MOSFETs (VDMOSFETs). In addition, UMOSFETs have higher channel density and mobility than VDMOSFETs due to their ability to form vertical channels on the trench sidewalls and their ability to reduce cell pitch [3-7]. However, there are two main drawbacks to UMOSFETs. First, they have a relatively large reverse transfer capacitance $\left(C_{r s s}\right)$. For high-frequency applications, devices must have a small Miller plateau $\left(Q_{G D}\right)$ and $C_{r s s}$ [8]. Since $Q_{G D}$ and $C_{r s s}$ are determined by the overlap between the gate and the drain, the gate-trench structure has a relatively large $C_{r s s}$. As such, it is necessary to reduce the device $C_{r s s}$ to ensure high power efficiency and low energy loss in high frequency operations. The second problem with UMOSFETs is the appearance of gate oxide reliability issues that arise from the gate oxide at the bottom of the trench when UMOSFET operates in the off-state. Because SiC, a wide bandgap material, has a small offset between the conduction band and the valance band with respect to the $\mathrm{SiC}$ and the gate oxide, Fowler Nordheim tunneling (FN tunneling) will occur in the electric field (generally over $3 \mathrm{MV} / \mathrm{cm}$ ) smaller than $\mathrm{Si}(\sim 6 \mathrm{MV} / \mathrm{cm})$. This FN tunneling current leads to oxide degradation [9-11]. Therefore, in the case of SiC UMOSFETs, it is very important to suppress electric field crowding at the gate oxide edge. To address this problem, a structure which includes a gate trench bottom P+ shielding region (BPR) has been proposed [12-15]. Various other structures have been proposed additionally to reduce the electric field of the gate oxide [16-19]. Infineon's CoolSiC 
and Rohm's Double Trench structure were also commercialized at a $1.2 \mathrm{kV}$ class [20-22]. Among them, the double trench structures have been most actively studied in recent years with regard to their dynamic properties and reliability [23-25]. In the case of the double trench structure, the source region and gate are both trenched. As a result, the electric field is not concentrated in the gate trench region. As a variant of the double trench, a source trench structure for distributing the electric field through thermally grown oxide has been proposed [26]. However, the dynamic characteristics of the $1700 \mathrm{~V}$ source trench MOSFET structure have not been actively discussed. In this study, we researched the switching characteristics of the 1700 V UMOSFET, Double Trench MOSFET (DT-MOSFET), and Source Trench MOSFET (ST-MOSFET) structures.

\section{Device Structures}

Figure 1 shows the three structures considered in this paper. Figure 1a is the conventional UMOSFET (C-UMOSFET), and Figure 1b,c are DT-MOS and ST-MOS, respectively. The device parameters of each structure have been optimized for static characteristics while the BPR is grounded. In addition, a depletion stopping layer (DSL) [27], also known as a current spreading layer (CSL) [28,29], is added. The DSL improves the on-state characteristics by suppressing the expansion of the depletion region in the JFET region. The cell pitch of each structure is $5.55 \mu \mathrm{m}$, and the total thickness of the epi-layer is $18 \mu \mathrm{m}$. The thickness of the BPR is $0.3 \mu \mathrm{m}$, and the gate trench width and depth are $1.55 \mu \mathrm{m}$ and $1.5 \mu \mathrm{m}$, respectively. In the case of DT-MOS, the source trench width is $0.5 \mathrm{um}$, the depth is $1.5 \mu \mathrm{m}$, and the thickness of the P+ shielding region of the source trench is $0.3 \mu \mathrm{m}$. In the case of ST-MOS, the source trench width is $0.5 \mu \mathrm{m}$, the depth is $2.4 \mu \mathrm{m}$, and the source oxide thickness is $0.1 \mu \mathrm{m}$. In addition, the concentration of the epi layer of each structure is $3 \times 10^{15} \mathrm{~cm}^{-3}, 5 \times 10^{15} \mathrm{~cm}^{-3}$, and $5 \times 10^{15} \mathrm{~cm}^{-3}$ for C-UMOS, DT-MOS, and ST-MOS, respectively. Additional device parameters are listed in Table 1.

In the next section, the characteristics of each structure are described. Static characteristics were simulated using Synopsys TCAD, and dynamic characteristics were analyzed through mixed mode simulation [30]. Electron/hole continuity equations and Poisson equation are solved with Shockley-Read-Hall recombination and Auger recombination model. The doping dependency, high field velocity saturation and mobility degradation are included in the mobility model. In particular, the Lombardi model was considered for the interface that affects the channel mobility [31]. Bandgap narrowing, anisotropic material properties, and incomplete ionization effects of each structure were considered [32,33].

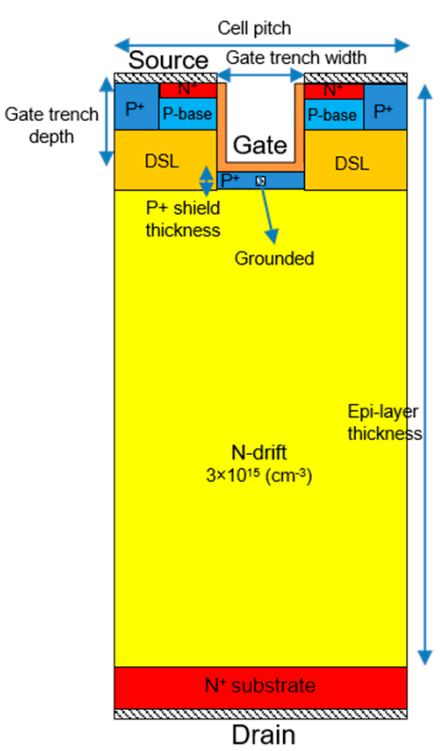

(a)

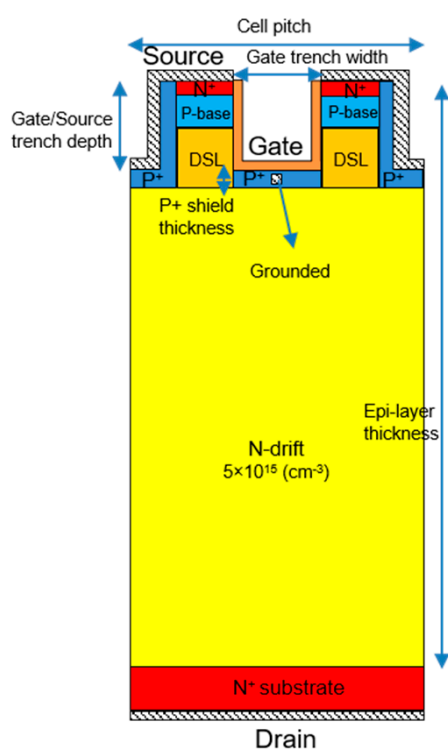

(b)

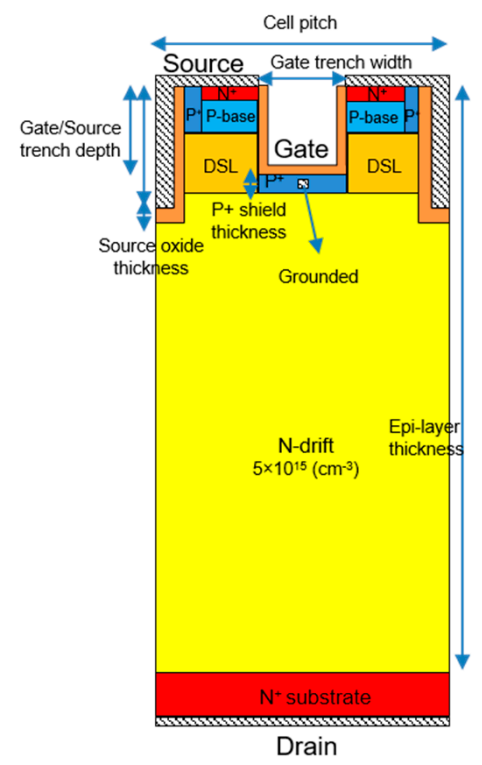

(c)

Figure 1. Schematic cross-sectional view of (a) C-UMOSFET, (b) DT-MOSFET, and (c) ST-MOSFET. 
Table 1. Device parameter of each structure.

\begin{tabular}{cccc}
\hline Parameter & C- & DT- & ST- \\
\hline Cell pitch $(\mu \mathrm{m})$ & 5.55 & 5.55 & 5.55 \\
Gate-trench width $(\mu \mathrm{m})$ & 1.55 & 1.55 & 1.55 \\
Gate-trench depth $(\mu \mathrm{m})$ & 1.5 & 1.5 & 1.5 \\
P-base width $(\mu \mathrm{m})$ & 2 & 2 & 2 \\
P+ shield width $(\mu \mathrm{m})$ & 1.55 & 1.55 & 1.55 \\
Channel length $(\mu \mathrm{m})$ & 0.5 & 0.5 & 0.5 \\
Gate oxide thickness $(\mu \mathrm{m})$ & 0.05 & 0.05 & 0.05 \\
Epi-layer thickness $(\mu \mathrm{m})$ & 18 & 18 & 18 \\
P+ shield thickness $(\mu \mathrm{m})$ & 0.3 & 0.3 & 0.3 \\
N-sub thickness $(\mu \mathrm{m})$ & 1 & 1 & 1 \\
Source-trench width $(\mu \mathrm{m})$ & - & 0.5 & 0.5 \\
Source-trench depth $(\mu \mathrm{m})$ & - & 1.5 & 2.4 \\
Source oxide thickness $(\mu \mathrm{m})$ & - & - & 0.1 \\
Source doping concentration $\left(\mathrm{cm}^{-3}\right)$ & $1 \times 10^{19}$ & $1 \times 10^{19}$ & $1 \times 10^{19}$ \\
P-base doping concentration $\left(\mathrm{cm}^{-3}\right)$ & $1 \times 10^{17}$ & $1 \times 10^{17}$ & $1 \times 10^{17}$ \\
P+ shield doping concentration $\left(\mathrm{cm}^{-3}\right)$ & $5 \times 10^{18}$ & $5 \times 10^{18}$ & $5 \times 10^{18}$ \\
Epi-layer doping concentration $\left(\mathrm{cm}^{-3}\right)$ & $3 \times 10^{15}$ & $5 \times 10^{15}$ & $5 \times 10^{15}$ \\
N-sub doping concentration $\left(\mathrm{cm}^{-3}\right)$ & $1 \times 10^{19}$ & $1 \times 10^{19}$ & $1 \times 10^{19}$ \\
DSL doping concentration $\left(\mathrm{cm}^{-3}\right)$ & $1 \times 10^{16}$ & $1 \times 10^{16}$ & $1 \times 10^{16}$ \\
\hline
\end{tabular}

\section{Results and Discussion}

\subsection{Static Characteristics}

First, in order to facilitate normalization, the active area was assumed to be $1 \mathrm{~cm}^{2}$, and simulation of static characteristics was performed. Figure 2 shows the off-state characteristic curves of the three structures. The breakdown voltages are $1699 \mathrm{~V}, 1706 \mathrm{~V}$, and $1724 \mathrm{~V}$ for each C-UMOSFET, DT-MOSFET and ST-MOSFET, respectively. Figure 3 shows the breakdown voltage when the doping concentration of the epi-layer of each structure is varied. Each structure is designed to have the breakdown voltage close to $1700 \mathrm{~V}$ by controlling the doping concentration of the epi-layer. Figure 4 shows the on-state characteristic curves of the three structures when the gate voltage is $15 \mathrm{~V}$. Figure $4 \mathrm{a}$ is the on-state characteristic curves of the linear region with the drain voltage range of $0-25 \mathrm{~V}$, and $\mathrm{b}$ is the overall on-state characteristic curves with the drain voltage range of 0-800 V. In Figure $4 \mathrm{a}$, the specific on-resistance at a low $V_{D}$ of the C-UMOSFET, DT-MOSFET, and ST-MOSFET are $3.37 \mathrm{~m} \Omega \cdot \mathrm{cm}^{2}, 3.57 \mathrm{~m} \Omega \cdot \mathrm{cm}^{2}$, and $2.52 \mathrm{~m} \Omega \cdot \mathrm{cm}^{2}$ (at $V_{G}=15 \mathrm{~V}$ and $I_{D}=20 \mathrm{~A}$ ), respectively. From Figure $4 \mathrm{~b}$, the quasi-saturation current [34] was highest for C-UMOSFET and lowest for DT-MOSFET. Due to the trenched source region, the width of the JFET region of the DT-MOSFET and ST-MOSFET is smaller than that of the C-UMOSFET. Since the current path decreases in proportion to the JFET width, the quasi-saturation current of DT-MOSFET and ST-MOSFET is reduced compared to the C-UMOSFET. The FOM $\left(\mathrm{BV}^{2} / R_{o n-s p}\right)$ [35], which represents the trade-off relationship of static characteristics, was calculated as $856.6 \mathrm{MW} / \mathrm{cm}^{2}, 815.2 \mathrm{MW} / \mathrm{cm}^{2}$, and $1179.4 \mathrm{MW} / \mathrm{cm}^{2}$ for the three structures, C-UMOSFET, DT-MOSFET, and ST-MOSFET, respectively.

Figure 5 shows the off-state gate oxide electric field distributions of each structure when $V_{G}=0 \mathrm{~V}$ and $V_{D}=1200 \mathrm{~V}$. The maximum gate oxide electric field $\left(\mathrm{E}_{\mathrm{ox}-\max }\right)$ is $1.1 \mathrm{MV} / \mathrm{cm}$ for the C-UMOSFET, $0.6 \mathrm{MV} / \mathrm{cm}$ for the DT-MOSFET, and $0.7 \mathrm{MV} / \mathrm{cm}$ for the ST-MOSFET. The grounded BPR applied to all three structures effectively blocks the electric field at gate oxide, reducing the $\mathrm{E}_{\mathrm{Ox} \text {-max }}$. In the case of the DT-MOSFET and ST-MOSFET, not only the BPR but also the trenched source region disperses the electric field applied to the gate oxide, further reducing the $\mathrm{E}_{\mathrm{ox} \text {-max }}$. Figure 6 shows the transfer characteristic curves of the three structures at $V_{D}=20 \mathrm{~V}$. As shown, at the same given gate voltage, the current handling capability varies with the JFET width. The wider the JFET width, the larger the drain current at the same gate voltage. Furthermore, the threshold voltages $\left(V\right.$ th) calculated at $V_{D}=20 \mathrm{~V}$ and $I_{D}=1 \mathrm{~A}$ are $5.74 \mathrm{~V}, 5.75 \mathrm{~V}$, and $5.75 \mathrm{~V}$ for each structure. Since the doping concentration and depth of the P-base were kept constant, there was little $V$ th shift. The overall static performance of the three structure is 
summarized in Table 2. Figure 7a shows the change in the threshold voltage of each structure as the temperature varies, and the threshold voltage shows the negative temperature coefficient [36]. As the lattice temperature increases from $300 \mathrm{~K}$ to $500 \mathrm{~K}$, the threshold voltage decreases due to the increase in intrinsic carrier concentration [37]. In all three structures, the threshold voltage at $500 \mathrm{~K}$ decreases by nearly $24 \%$ compared to the value at $300 \mathrm{~K}$. Figure $7 \mathrm{~b}$ shows the specific on-resistance versus temperature. As seen in Figure $7 \mathrm{~b}$, the DT-MOSFET is the least temperature dependent, increasing by approximately $140 \%$ at $500 \mathrm{~K}$, with respect to its on-resistance at $300 \mathrm{~K}$. For the ST-MOSFET and C-UMOSFET, the on-resistance at $500 \mathrm{~K}$ increases by $160 \%$ and $180 \%$, respectively, compared to the on-resistance at $300 \mathrm{~K}$.

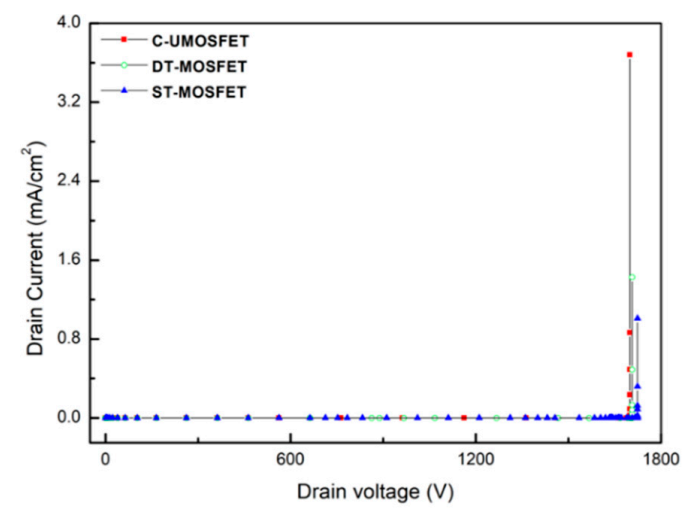

Figure 2. Off-state breakdown characteristic cures of each structure.

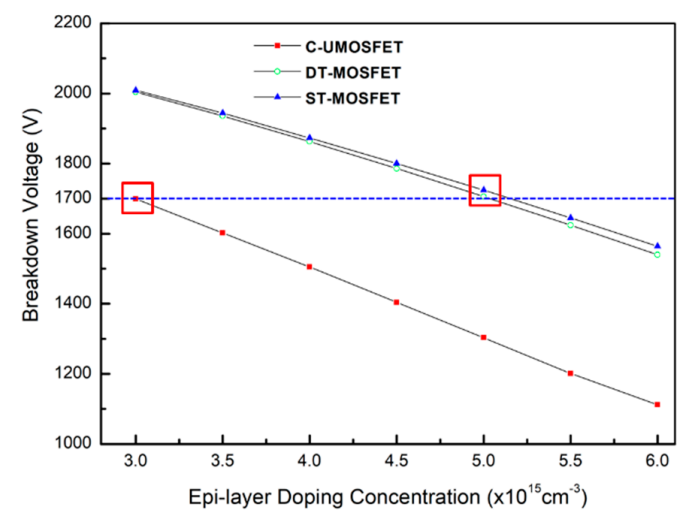

Figure 3. Variation of breakdown voltage of each structure with epi-layer doping concentration.

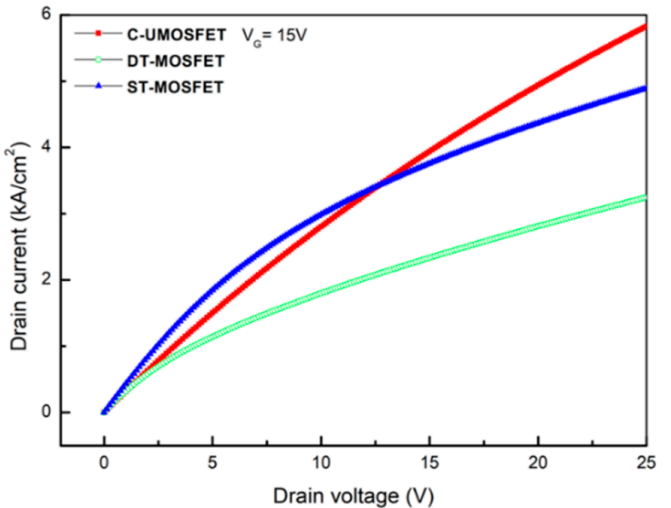

(a)

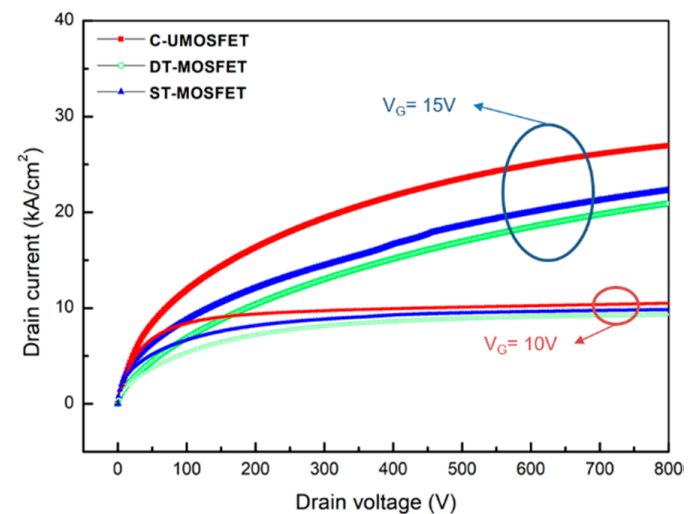

(b)

Figure 4. (a) On-state output characteristic curves in the linear region of each structure with the drain voltage range of $0-25 \mathrm{~V}$ and (b) Overall on-state output characteristic curves of each structure with the drain voltage range of $0-800 \mathrm{~V}$. 


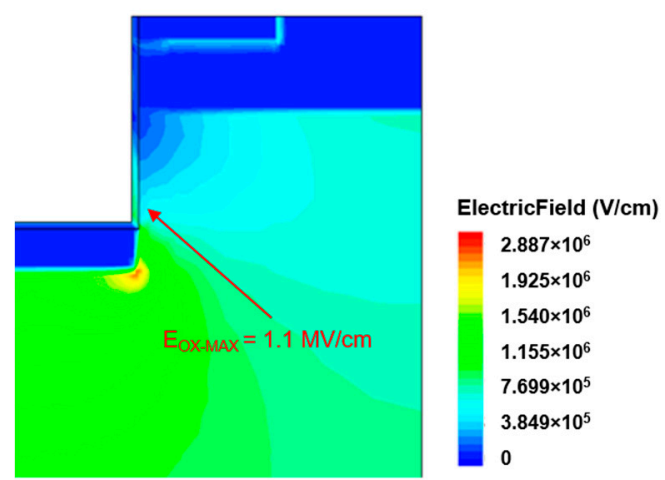

(a)

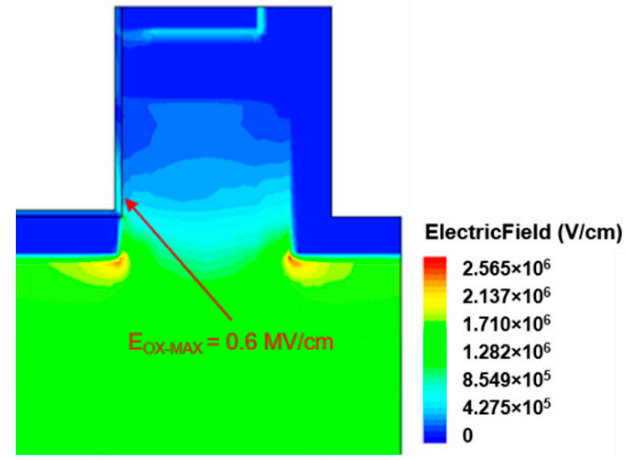

(b)

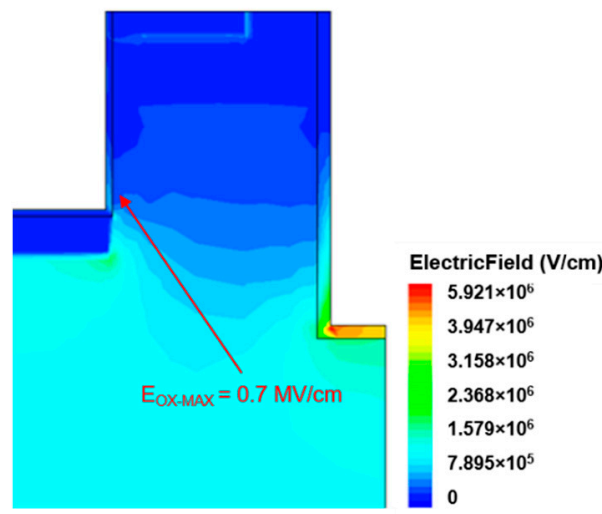

(c)

Figure 5. Off-state gate oxide electric field distribution of (a) C-UMOSFET, (b) DT-MOSFET, and (c) STMOSFET at $V_{D}=1200 \mathrm{~V}$.

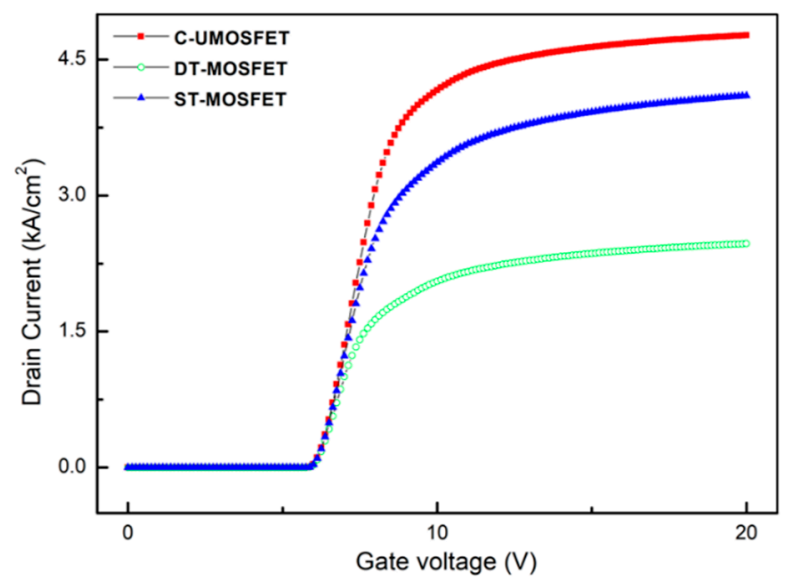

Figure 6. Transfer characteristics of each structure at $V_{D}=20 \mathrm{~V}$.

Table 2. Static performance of each structure.

\begin{tabular}{cccc}
\hline Parameter & C- & DT- & ST- \\
\hline Breakdown voltage $[\mathrm{V}]$ & 1699 & 1706 & 1724 \\
$R_{O N-S P}\left[\mathrm{~m} \Omega \cdot \mathrm{cm}^{2}\right]$ & 3.37 & 3.57 & 2.52 \\
E $\left._{\text {OX-MAX }} @ V G=0 \mathrm{~V}, V D=1200 \mathrm{~V}\right)[\mathrm{MV} / \mathrm{cm}]$ & 1.11 & 0.62 & 0.72 \\
$V_{T H}[\mathrm{~V}]$ & 5.74 & 5.75 & 5.75 \\
DC-FOM $\left(\mathrm{BV}^{2} / R_{O N-S P}\right)\left[\mathrm{MW} / \mathrm{cm}^{2}\right]$ & 857 & 815 & 1179 \\
\hline
\end{tabular}




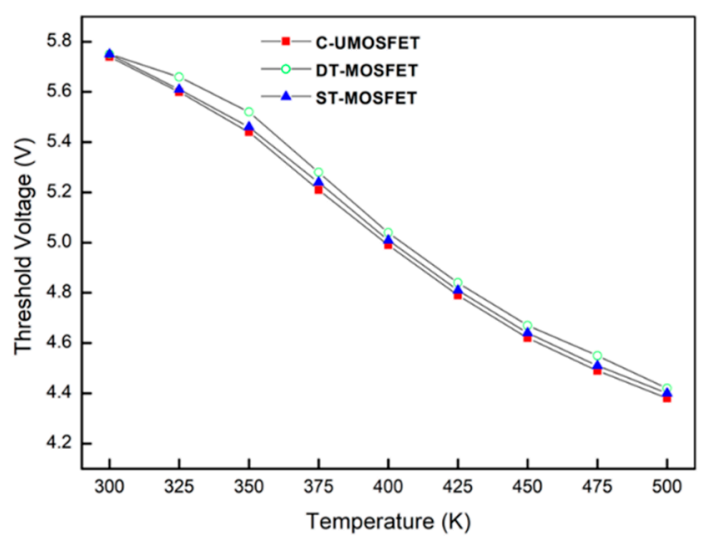

(a)

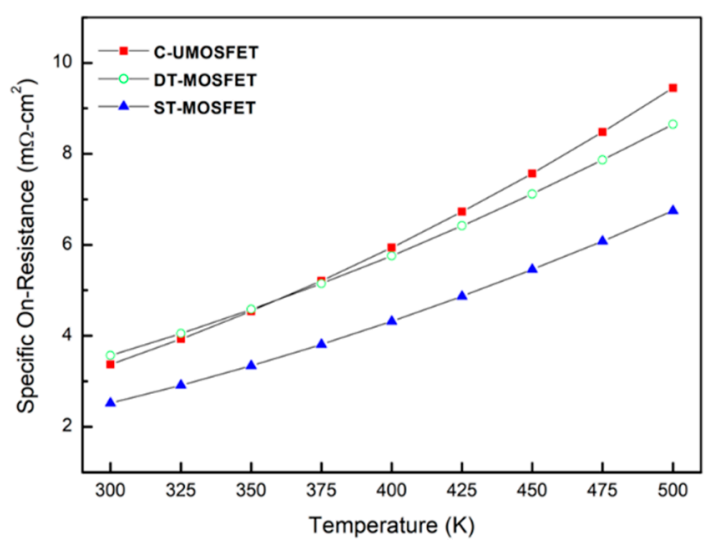

(b)

Figure 7. (a) Threshold voltage versus temperature of each structure taken at $V_{D}=20 \mathrm{~V}$ and $I_{D}=1 \mathrm{~A}$;

(b) Specific on-resistance versus temperature of each structure taken at $V_{G}=15 \mathrm{~V}$ and $I_{D}=20 \mathrm{~A}$.

\subsection{Terminal Capacitance Characteristics}

In this section, the simulation conditions for capacitance extraction are set such that the active area is $1 \mathrm{~cm}^{2}$, the ac small signal is $1 \mathrm{MHz}$, the gate voltage is fixed at $0 \mathrm{~V}$, and the drain voltage sweeps from 0-600 V. Before analyzing the terminal capacitance of the three structures, the effect of BPR on the capacitance was analyzed. Figure 8 shows the capacitance for both ground and floating BPR and for DSL in the C-UMOSFET. The grounded BPR in contact with the source increases the overlapping area between the gate and the source. Thus, in the case of the grounded BPR, the input capacitance $\left(C_{i s s}: C_{i s s}\right.$ $=C_{G S}+C_{G D}$ ) is higher than that when no BPR is used or when a floating BPR is applied. However, the floating BPR causes dynamic degradation due to its charge storage mechanism [38], and when no BPR is applied to the C-UMOSFET, there is increased degradation of the dynamic characteristics due to hot hole injections that arise from the high electric field in the gate oxide [24]. On the other hand, in the case of grounded BPR, $C_{r s s}$, which plays the most important role in switching energy loss, is effectively reduced. The grounded BPR blocks the electric field between the bottom gate and the drain and screens the charge coupling [38]. Therefore, only the capacitance between the side gate oxide and the drain contributes to the $C_{r s s}$ [12]. When the DSL is added, the $C_{r s s}$ is nearly identical as when the ground BPR is applied, excluding a slight increase at low drain voltages.

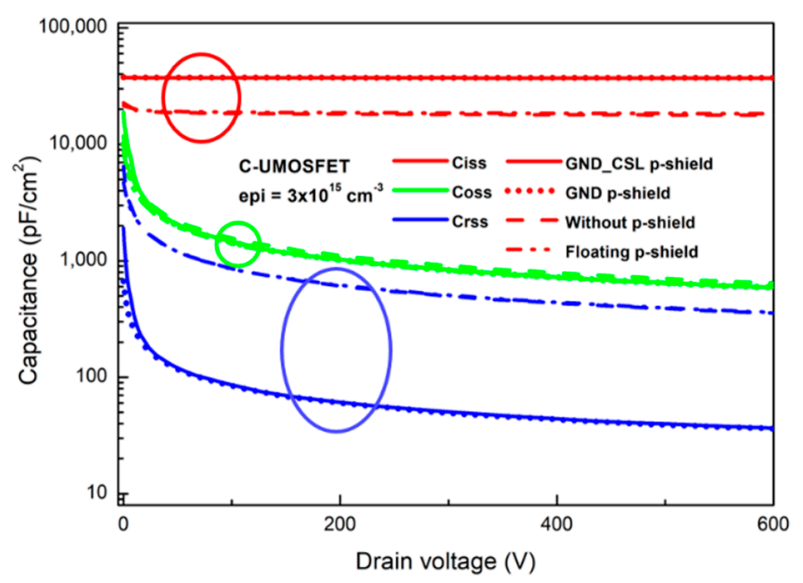

Figure 8. Terminal capacitance of C-UMOSFET. The effect of BPR and DSL on the capacitance is observed. 
In the UMOSFET structure, the gate-drain capacitance $\left(C_{G D}\right.$ or $\left.C_{r s s}\right)$ is the series connection between the gate oxide capacitance and the depletion capacitance. According to a previous study on the modeling of gate-drain capacitance in UMOSFET structures, the equation for $C_{G D}$ is as follows [39,40]:

$$
C_{G D}=\left(\frac{t_{W}+2 t_{D}^{\prime}}{t_{c e l l}}\right)\left[\frac{C_{G O X} C_{D}}{C_{G O X}+C_{D}}\right]
$$

where $t_{D}^{\prime}$ is the trench depth not overlapping the p-base region, $t_{W}$ is the trench width, $t_{\text {cell }}$ is the cell pitch, $C_{o x}$ is the gate oxide capacitance, and $C_{D}$ is the depletion capacitance. However, in the case of a structure in which the source region is trenched, such as DT-MOSFETs and ST-MOSFETs, it is difficult to intuitively analyze the $C_{G D}$ due to the geometric complexity of the structure. Recently, X. Luo et al. [40] illustrated that the $C_{G D}$ operates as a serial connection between the gate-source capacitance and the drain-source capacitance. The gate-drain capacitance equation in Double Trench MOSFET Structure (without BPR) claimed in his paper are:

$$
C_{G D}=\left(C_{G S}{ }^{-1}+C_{D S}{ }^{-1}\right)^{-1}+C_{G D, b o t t o m}
$$

where $C_{G S}$ is the gate-source capacitance, $C_{D S}$ is the drain-source capacitance and $C_{G D \text {,bottom }}$ is the gate bottom-drain capacitance. In DT-MOSFET with BPR, $C_{G D \text {,bottom }}$ is negligible, so $C_{G D}=\left(C_{G S}{ }^{-1}+\right.$ $\left.C_{D S}{ }^{-1}\right)^{-1}$. However, this mechanism may contradict the results shown in Figure 9. Figure 9 plots the $C_{G D}$ as function of the trench depth of the source region in the DT-MOSFET. In Figure 9, $C_{G D}$ decreases as $\mathrm{L}$ (source trench depth) increases. When L increases, the overlapping area between the gate and the source increases. As such, $C_{G S}$ increases and at the same time, the distance between the drain and the source decreases, leading to an increase in $C_{D S}$. So, according to (2), as $\mathrm{L}$ increases, $C_{G D}$ should increase. This contradicts the simulation results in Figure 9, where $C_{G D}$ decreases as L increases.

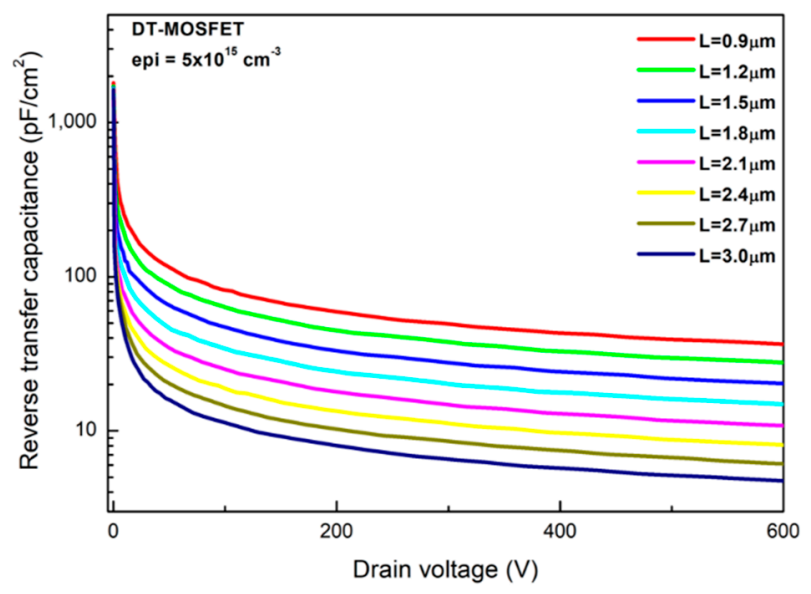

Figure 9. Reverse transfer capacitance of DT-MOSFET varying in source trench depth.

Figure 10 shows the capacitance distribution of the three structures. Depletion capacitance is considered to be the serial connection of the JFET capacitance $\left(C_{J F E T}\right)$ and the Drift capacitance $\left(C_{\text {Drift }}\right)$. The modified gate-drain capacitance equation is given follows:

$$
C_{G D}=\left(C_{O X}^{-1}+C_{J F E T}^{-1}+C_{\text {Drift }}^{-1}\right)^{-1}
$$

Using this model, the capacitance of the trench MOSFET can be analyzed intuitively. First, the gate oxide thickness of the three structures is the same, so $C_{o x}$ is the same. Before the depletion region is fully extended to the drift region, at a low drain voltage, the depletion regions of the DT-MOSFET and ST-MOSFET extend further than that of the C-UMOSFET due to their trenched source regions. Therefore, the $C_{\text {Drift }}$ of DT-MOSFET and ST-MOSFET is smaller than that of C-UMOSFET. Indeed, 
the DT-MOSFET has the smallest $C_{\text {Drift }}$ of the three structures because its depletion region is wider than that of the ST-MOSFET due to the P-shielding region below the source region. In the case of the $C_{J F E T}$, it is proportional to the JFET width. The charge in the JFET region is proportional to the JFET width, and the $C_{J F E T}$ is proportional to the charge in the JFET region. Therefore, $C_{J F E T}$ is smallest in DT-MOSFET and largest in C-UMOSFET. In addition, at a high drain voltage, the drift region is fully depleted and the $C_{\text {Drift }}$ of the three structure is nearly the same. Thus, $C_{G D}$ is determined by the $C_{J F E T}$.

Figure 11 plots the terminal capacitance of the three structures. In Figure 11a, the $C_{i s s}$ of the three structures are almost the same. In the DT-MOSFET and ST-MOSFET, the trenched source region for improving the static characteristics increases the overlapping area between the gate and the source. However, as shown in Figure 12, the capacitance between the bottom gate and the BPR is the largest of all $C_{G S}$ components, and BPR is applied to all three structures, so the $C_{i s s}$ of the three structures is not significantly different. The output capacitance $\left(C_{o s s}: C_{o s s}=C_{D S}+C_{G D}\right)$, which depends on the distance between the drain and source, is also not significantly different, though the C-UMOSFET has the smallest $C_{\text {OSS }}$. In the case of $C_{r s s}$, according to the previous analysis, the $C_{r S s}$ of the DT-MOSFET is the smallest, and the $C_{r s s}$ of the C-UMOSFET is the largest. At $V_{D}=600 \mathrm{~V}$, the $C_{r s s}$ of DT-MOSFET and ST-MOSFET decreases by $44 \%$ and $24 \%$, respectively, compared to the value of C-UMOSFET. The capacitance simulation results for each structure are shown in Table 3.

Table 3. Dynamic performance of each structure.

\begin{tabular}{cccc}
\hline Parameter & C- & DT- & ST- \\
\hline$C_{I S S}\left(@ V_{D}=600 \mathrm{~V}, \mathrm{f}=1 \mathrm{MHz}\right)\left[\mathrm{nF} / \mathrm{cm}^{2}\right]$ & 37 & 37.3 & 36.2 \\
$C_{O S S}\left(@ V_{D}=600 \mathrm{~V}, \mathrm{f}=1 \mathrm{MHz}\right)\left[\mathrm{pF} / \mathrm{cm}^{2}\right]$ & 590 & 763 & 765 \\
$C_{R S S}\left(@ V_{D}=600 \mathrm{~V}, \mathrm{f}=1 \mathrm{MHz}\right)\left[\mathrm{pF} / \mathrm{cm}^{2}\right]$ & 36.5 & 20.3 & 27.7 \\
$Q_{G}\left[\mathrm{nC} / \mathrm{cm}^{2}\right]$ & 839 & 805 & 813 \\
$Q_{G D}\left[\mathrm{nC} / \mathrm{cm}^{2}\right]$ & 115 & 81 & 89 \\
HF-FOM $<R_{O N-S P} \times Q_{G}>[\mathrm{m} \Omega \cdot \mathrm{nC}]$ & 2827 & 2874 & 2049 \\
HF-FOM $<R_{O N-S P} \times Q_{G D}>[\mathrm{m} \Omega \cdot \mathrm{nC}]$ & 388 & 289 & 224 \\
\hline
\end{tabular}

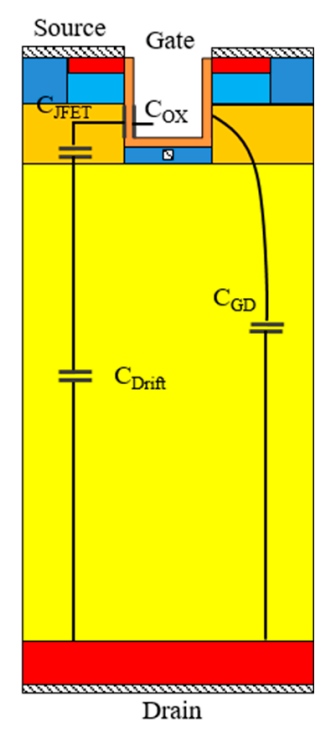

(a)

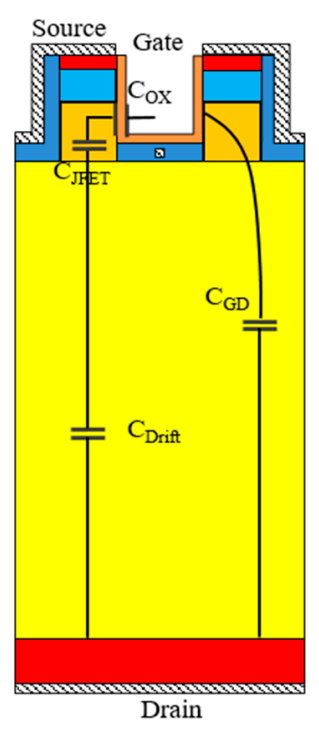

(b)

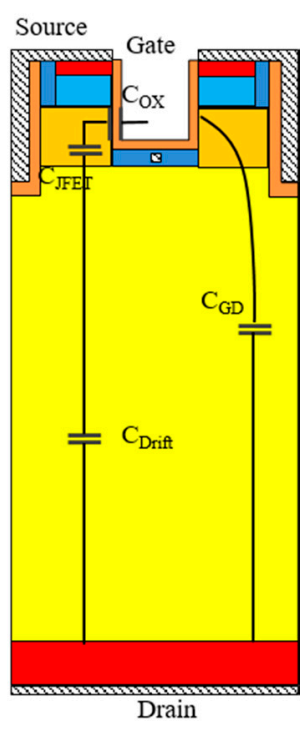

(c)

Figure 10. Capacitance distribution for (a) C-UMOSFET, (b) DT-MOSFET, and (c) ST-MOSFET. 


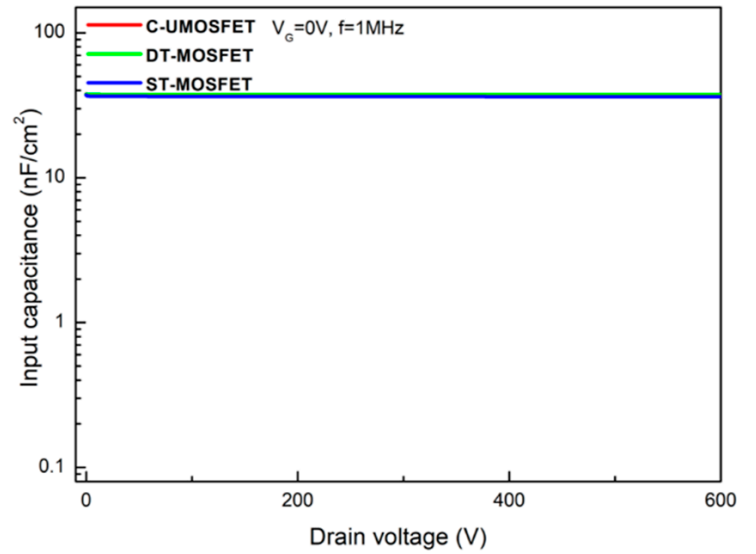

(a)

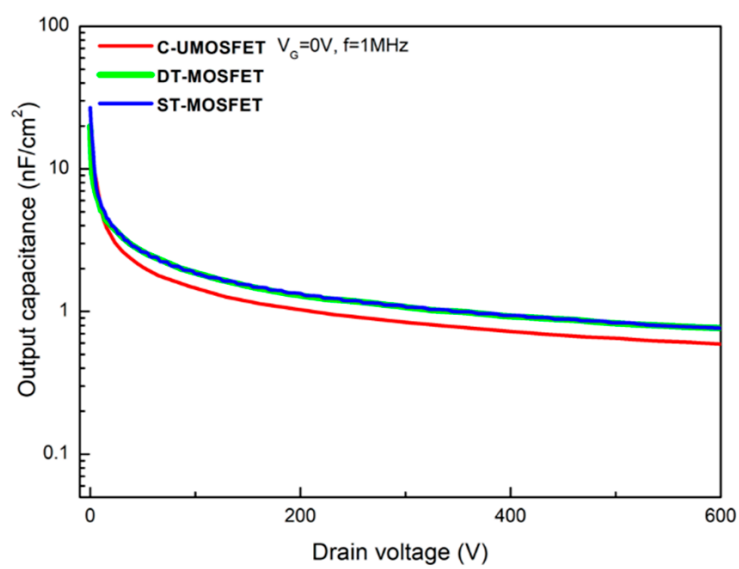

(b)

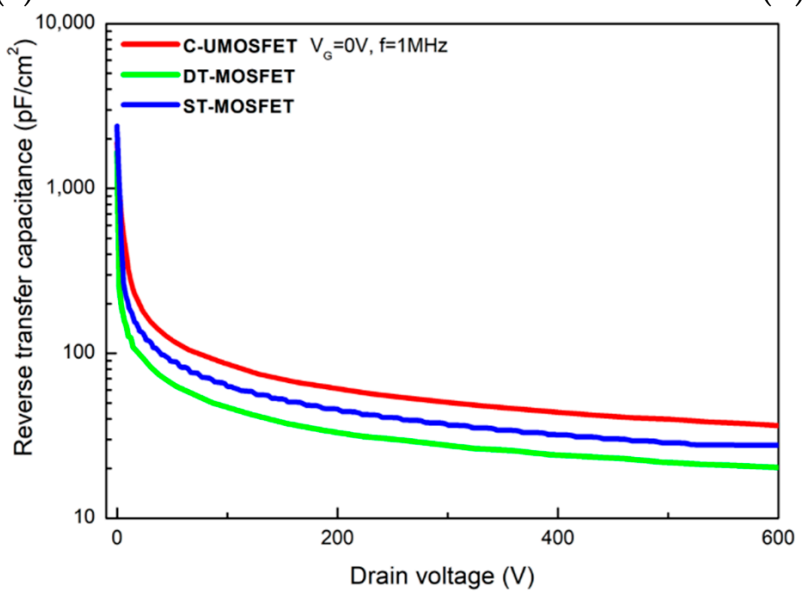

(c)

Figure 11. (a) Input capacitance, (b) output capacitance, and (c) reverse transfer capacitance of each structure.

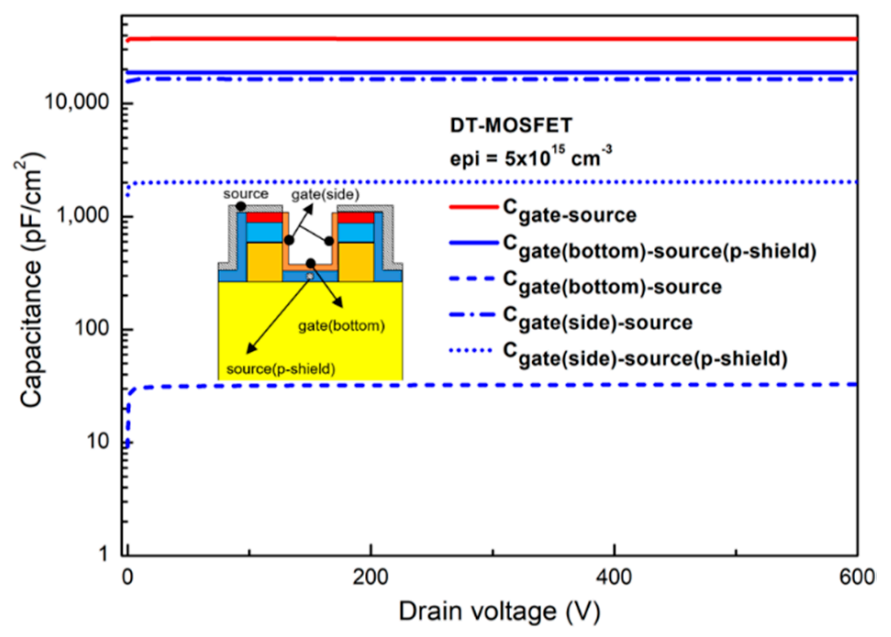

Figure 12. Gate-source capacitance distribution of DT-MOSFET.

\subsection{Dynamic Charateristics}

Figure 13a shows the gate charge curves of the three structures. The test circuit is shown in Figure 13b and a constant current of $100 \mathrm{~mA}$ is used to charge the gate. The active area of the device under test (DUT) for gate charge simulation was set to $1 \mathrm{~cm}^{2}$. In addition, test conditions were set so that the supplying voltage $\left(V_{D D}\right)$ was $1200 \mathrm{~V}$ and the load current $\left(I_{D}\right)$ was $20 \mathrm{~A}$. The gate-drain charge ( $Q_{G D}$ or Miller plateau) is one of the key parameters that can determine the switching speed of the device and is dependent 
on $C_{G D}$. The extracted $Q_{G D}$ values are $114.8 \mathrm{nC} / \mathrm{cm}^{2}, 80.6 \mathrm{nC} / \mathrm{cm}^{2}, 89.2 \mathrm{nC} / \mathrm{cm}^{2}$ for C-UMOSFET, DT-MOSFET, and ST-MOSFET, respectively. In addition, the extracted total gate charge $\left(Q_{G}\right)$ values are $839 \mathrm{nC} / \mathrm{cm}^{2}, 805.1 \mathrm{nC} / \mathrm{cm}^{2}, 812.7 \mathrm{nC} / \mathrm{cm}^{2}$ for C-UMOSFET, DT-UMOSFET, and ST-UMOSFET. This result is proportional to the extracted results of $C_{G D}$. The HF-FOM $\left(R_{O N-S P} \times Q_{G D}\right)$ of DT-MOSFET and ST-MOSFET is $289 \mathrm{~m} \Omega \cdot \mathrm{nC}, 224 \mathrm{~m} \Omega \cdot \mathrm{nC}$, respectively, which is improved by $26 \%$ and $42 \%$ compared to C-UMOSFET.

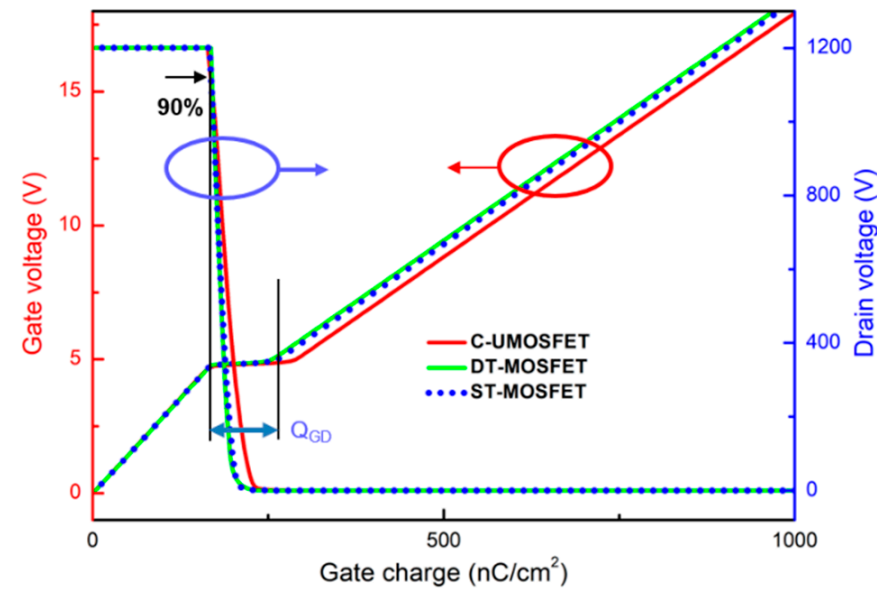

(a)

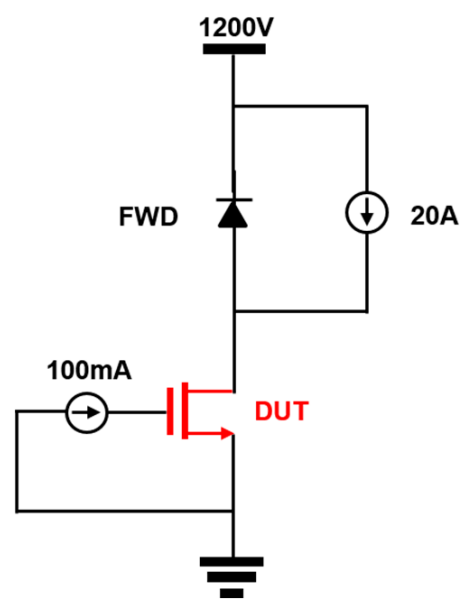

(b)

Figure 13. (a) Gate charge characteristics of each structure; (b) Test circuit.

Table 3 summarizes the results including the values for terminal capacitance, gate charge, and HF-FOMs, which are significant parameters for high frequency performance $[8,37,41]$.

Finally, the switching performance parameter of the device was extracted through a double-pulse test (DPT). The active areas of all the DUT were set to $0.3 \mathrm{~cm}^{2}$ [42], which is similar to that of commercial devices [43]. Figure 14a plots the full waveform of the ST-MOSFET. Figure 14b shows the test circuit in the three structures. The gate resistance is set to $10 \Omega$, and the gate voltage switched between $15 \mathrm{~V}$ and $-3 \mathrm{~V}$ for the on- and off-states. The stray inductance was assumed to be $10 \mathrm{nH}$. The load inductance was set to $300 \mu \mathrm{H}$, and the first gate voltage pulse lasted $5 \mu$ s so that the load current flow was $20 \mathrm{~A}$. The body diode of the same device as the DUT was used as a freewheeling diode, and the supply voltage was $1200 \mathrm{~V}$.

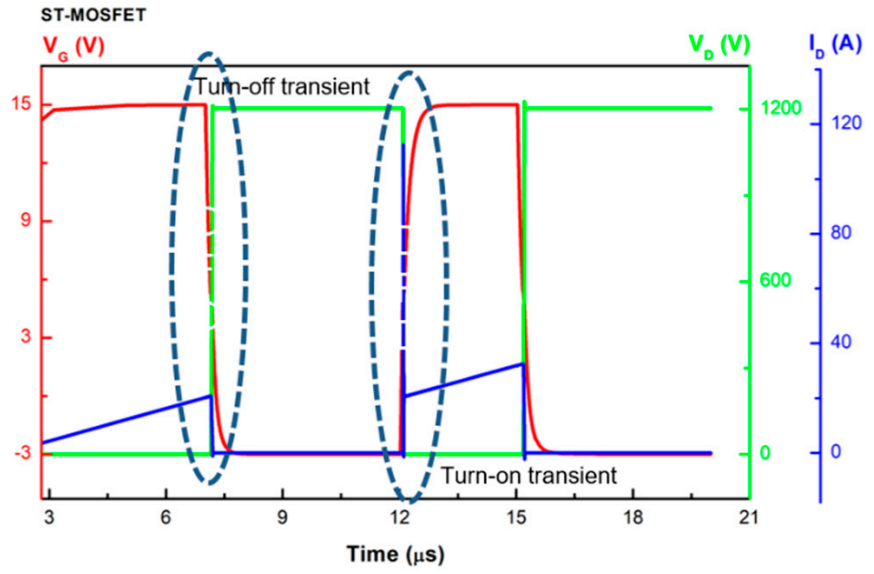

(a)

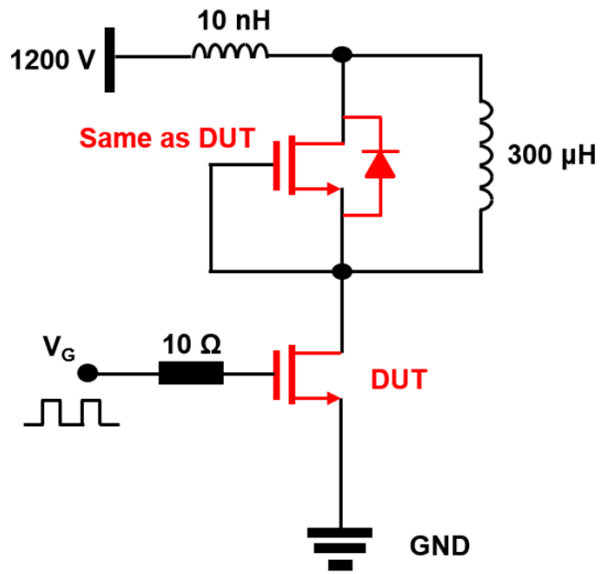

(b)

Figure 14. (a) Full DPT waveform of ST-MOSFET; (b) Test circuit. 
In this paper, turn-on time $\left(T_{O N}\right)$ and turn-off time $\left(T_{O F F}\right)$ are defined as follows [43-45].

$$
\begin{gathered}
T_{\text {ON }}=T_{D-O N}+T_{R} \\
T_{\text {OFF }}=T_{D-O F F}+T_{F}
\end{gathered}
$$

where $T_{D-O N}$ is the turn-on delay time (from $10 \%$ of $V_{G}$ to $90 \%$ of $V_{D}$ at the rising edge), $T_{R}$ is the rise time at the turn-on transient (from $90 \%$ of $V_{D}$ to $10 \%$ of $V_{D}$ at the rising edge), $T_{D \text {-OFF }}$ is the turn-off delay time (from $90 \%$ of $V_{G}$ to $10 \%$ of $V_{D}$ at the falling edge) and fall time at the turn-off transient (from $10 \%$ of $V_{D}$ to $90 \%$ of $V_{D}$ at the falling edge). Figure 15 shows the switching waveforms of each structure, and Table 4 summarizes the detailed switching performance data. The switching speed $\left(T_{O N}\right.$ and $T_{O F F}$ ) of the device is most affected by $C_{\text {iss }}$, and $T_{R}$ and $T_{F}$ are most dependent on $C_{G D}[37,41]$. In hard switching, $V_{D}$ and $I_{D}$ are swept during $T_{R}$ and $T_{F}$, so energy loss is dependent upon $T_{R}$ and $T_{F}$. In the previous section, we observed that the $C_{i s s}$ of DT-MOSFET and ST-MOSFET is almost the same as the value of C-UMOSFET. Therefore, the switching speed of DT-MOSFET and ST-MOSFET is maintained at the same level as C-UMOSFET. In addition, the $C_{G D}$ of DT-MOSFET and ST-MOSFET is superior to that of C-UMOSFET, which improves the switching energy loss. The switching energy loss of C-UMOSFET, DT-MOSFET, and ST-MOSFET are $827.1 \mu \mathrm{J}, 771.2 \mu \mathrm{J}$, and $806 \mu \mathrm{J}$, respectively. In addition, since the drain voltage sweeps from low to high at the falling edge of the turn-off transient, $T_{O F F}$ is relatively slower than $T_{O N}$. Moreover, since the body diode of each device was used as FWD, $E_{O N}$ includes the diode reverse recovery. Therefore, $E_{O N}$ is relatively larger than $E_{O F F}$.

Table 4. Switching performance of each structure.

\begin{tabular}{cccc}
\hline Parameter & C- & DT- & ST- \\
\hline$T_{D-O N}[\mathrm{~ns}]$ & 56.87 & 57.68 & 56.70 \\
$T_{R}[\mathrm{~ns}]$ & 13.18 & 10.48 & 10.73 \\
$T_{\text {ON }}[\mathrm{ns}]$ & 70.05 & 68.16 & 67.43 \\
$T_{D-O F F}[\mathrm{~ns}]$ & 135.1 & 137.4 & 132.7 \\
$T_{F}[\mathrm{~ns}]$ & 23.75 & 20.48 & 23.53 \\
$T_{\text {OFF }}[\mathrm{ns}]$ & 158.8 & 157.8 & 156.3 \\
$E_{\text {ON }}[\mu \mathrm{J}]$ & 655.3 & 610.7 & 637.5 \\
$E_{O F F}[\mu \mathrm{J}]$ & 171.8 & 160.6 & 168.5 \\
$E_{S W}[\mu \mathrm{J}]$ & 827.1 & 771.2 & 806.0 \\
\hline
\end{tabular}

The total power losses $P_{t}$ of the device consist of conduction losses and switching losses and are calculated as follows $[19,37,40]$ :

$$
P_{t}=d R_{o n-s p} I_{d}^{2}+f\left(E_{O N}+E_{O F F}\right)
$$

where $d$ is the duty cycle and $f$ is the switching frequency. Figure 16 shows the power losses which vary with the switching frequency when the duty cycle is 0.5 . As the switching frequency increases, the ratio of switching losses of total power losses increases. The power losses of C-UMOSFET, DT-MOSFET, and ST-MOSFET when operating at $200 \mathrm{kHz}$ are $552.1 \mathrm{~W} / \mathrm{cm}^{2}, 514.9 \mathrm{~W} / \mathrm{cm}^{2}$ and $537.8 \mathrm{~W} / \mathrm{cm}^{2}$, respectively. 


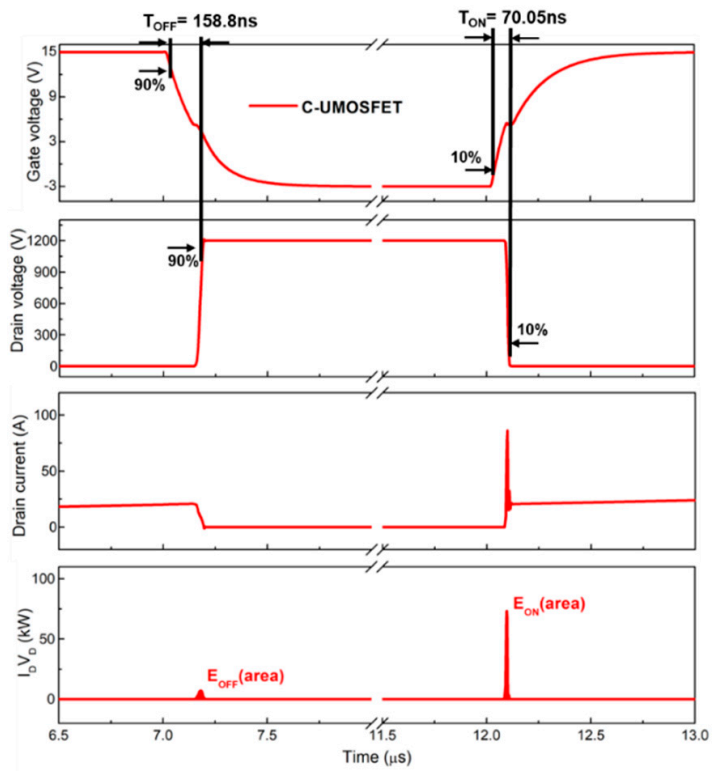

(a)
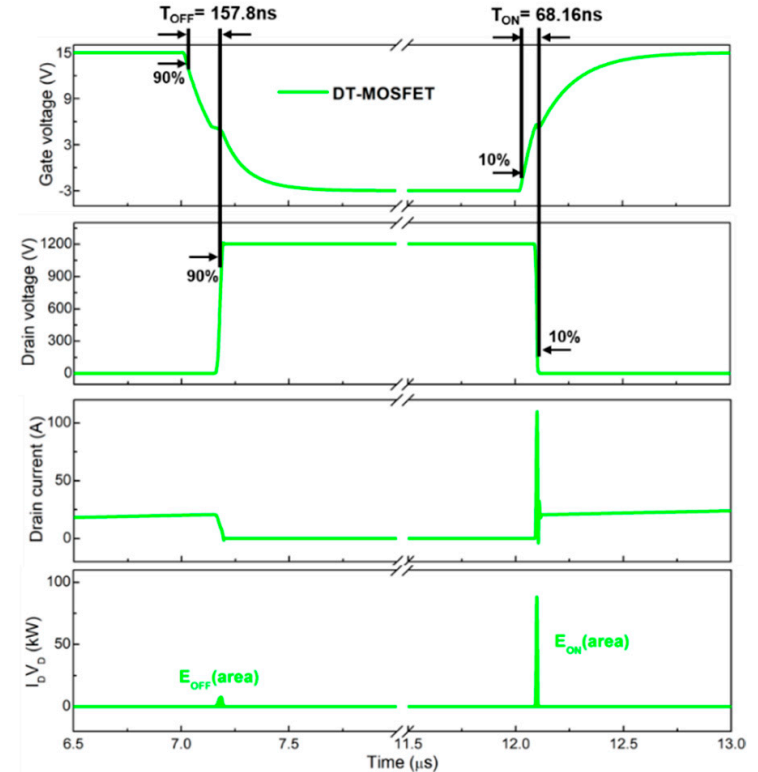

(b)

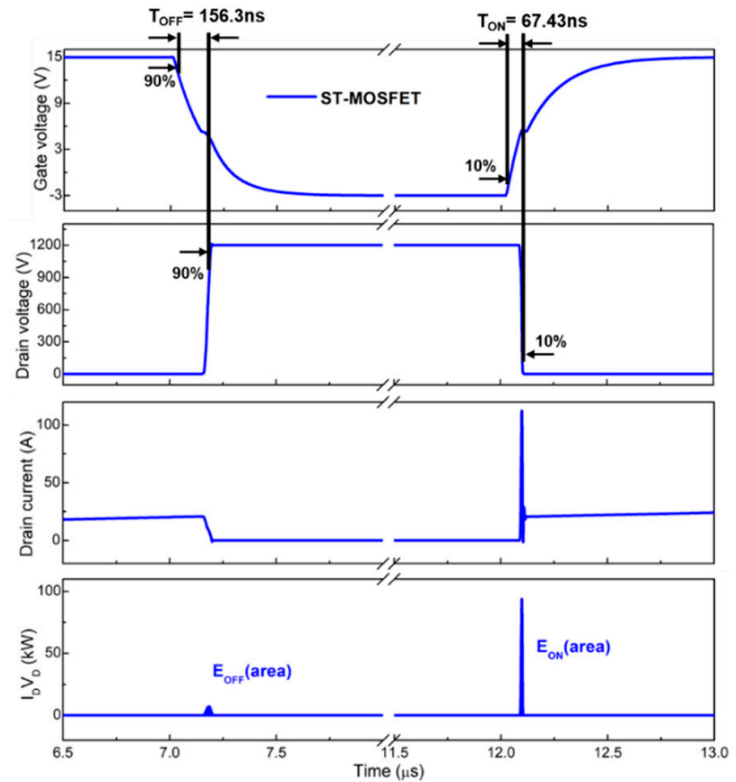

(c)

Figure 15. Switching waveform of (a) C-UMOSFET, (b) DT-MOSFET, and (c) ST-MOSFET.

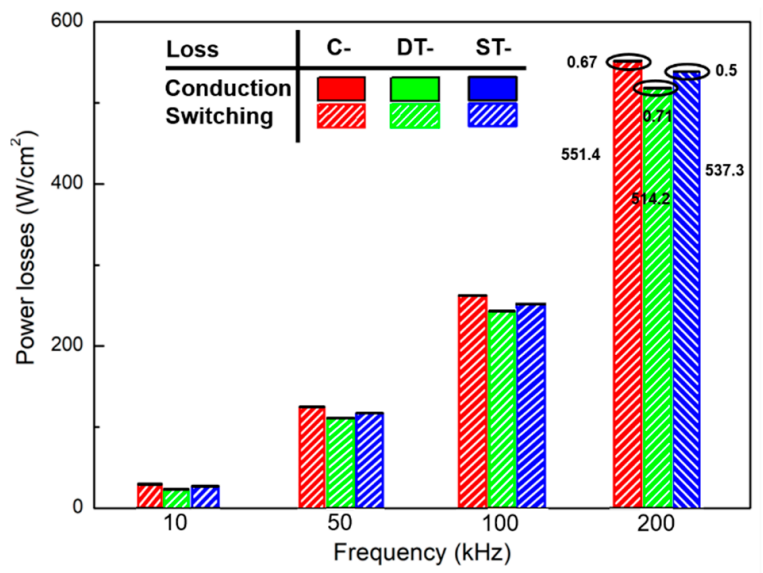

Figure 16. Comparison of power losses depending on switching frequency. 


\section{Conclusions}

In this paper, the static and dynamic performance of the 4H-SiC C-UMOSFET, DT-MOSFET and ST-MOSFET were compared through TCAD simulation. In static characteristics, the $R_{O N-S P}$ of the ST-MOSFET is $2.52 \mathrm{~m} \Omega \cdot \mathrm{cm}^{2}$, which is $25 \%$ lower than that of C-UMOSFET. Furthermore, the DC-FOM of the ST-MOSFET is $1179 \mathrm{MW} / \mathrm{cm}^{2}$, which is $37 \%$ higher than that of the C-UMOSFET. At $V_{D}=1200 \mathrm{~V}$, the Eox-max of the DT-MOSFET is $0.6 \mathrm{MV} / \mathrm{cm}$, which was $44 \%$ lower than that of the C-UMOSFET. To improve the static characteristics, both the DT-MOSFET and ST-MOSFET are trenched in the source region. For the same reason, the BPR is introduced in the three structures. The effect of the trenched source region and BPR on the capacitance was analyzed, and the dynamic characteristics of the three structures were compared. Due to the trenched source region, the overlapping area between the gate and source increases. Nevertheless, the capacitance between the gate and the BPR is largest of $C_{G S}$ components, so the $C_{i s s}$ is almost identical in all three structure. On the other hand, the $C_{G D}$ of DT-MOSFET and ST-MOSFET is reduced by $44 \%$ and $24 \%$, respectively, compared to C-UMOSFET. This is because the depletion region is expanded by the trenched source region. Since the $C_{G D}$ of DT-MOSFET and ST-MOSFET is superior to that of C-UMOSFET, it improves HF-FOM $\left(R_{O N-S P} \times C_{G D}\right)$. The HF-FOM $\left(R_{O N-S P} \times Q_{G D}\right)$ of DT-MOSFET and ST-MOSFET is $289 \mathrm{~m} \Omega \cdot \mathrm{nC}, 224 \mathrm{~m} \Omega \cdot \mathrm{nC}$, respectively, which is improved by $26 \%$ and $42 \%$ compared to C-UMOSFET. The switching speed of DT-MOSFET and ST-MOSFET are maintained at the same level as the C-UMOSFET. The switching energy loss and power loss of the DT-MOSFET and ST-MOSFET are slightly improved compared to C-UMOSFET.

Author Contributions: All authors contributed to this work. Investigation, J.C., K.K.; Methodology, J.C., K.K.; Supervision, J.C., K.K.; Writing-original draft, J.C.; Writing-review and editing, K.K. All authors have read and agreed to the published version of the manuscript.

Funding: This research received no external funding.

Acknowledgments: This research was supported by Samsung Electronics, the MSIT (Ministry of Science and ICT), Korea, under the ITRC (Information Technology Research Center) support program (IITP-2020-2018-0-01421) supervised by the IITP (Institute for Information \& communications Technology Promotion), and then the IDEC (IC Design Education Center).

Conflicts of Interest: The authors declare no conflict of interest.

\section{References}

1. Zhang, M.; Wei, J.; Jiang, H.; Chen, K.J.; Cheng, C.H. A new SiC trench MOSFET structure with protruded p-base for low oxide field and enhanced switching performance. IEEE Trans. Device Mater. Rel. 2017, 17, 432-437. [CrossRef]

2. Cooper, J.A.; Agarwal, A. SiC power-switching devices-The second electronics revolution? Proc. IEEE 2002, 90, 956-968. [CrossRef]

3. Ebihara, Y.; Ichimura, A.; Mitani, A.; Noborio, M.; Takeuchi, Y.; Mizuno, S.; Yamamoto, T.; Tsuruta, K. Deep-P Encapsulated 4HSiC Trench MOSFETs With Ultra Low RonQgd. In Proceedings of the IEEE 30th International Symposium on Power Semiconductor Devices and ICs (ISPSD), Chicago, IL, USA, 13-17 May 2018; pp. 44-48.

4. Cooper, J.; Melloch, M.; Singh, R.; Agarwal, A.; Palmour, J. Status and prospects for SiC power MOSFETs. IEEE Trans. Electron Devices 2002, 49, 658-664. [CrossRef]

5. Yano, H.; Nakao, H.; Hatayama, T.; Uraoka, Y.; Fuyuki, T. Increased Channel Mobility in 4H-SiC UMOSFETs Using On-Axis Substrates. Mater. Sci. Forum 2007, 556-557, 807-810. [CrossRef]

6. Banzhaf, C.T.; Grieb, M.; Trautmann, A.; Bauer, A.J.; Frey, L. Characterization of Diverse Gate Oxides on 4H-SiC 3D Trench-MOS Structures. Mater. Sci. Forum 2013, 740, 691-694. [CrossRef]

7. Kojima, T.; Harada, S.; Kobayashi, Y.; Sometani, M.; Ariyoshi, K.; Senzaki, J.; Takei, M.; Tanaka, Y.; Okumura, H. Self-aligned formation of the trench bottom shielding region in $4 \mathrm{H}-\mathrm{SiC}$ trench gate MOSFET. Jpn. J. Appl. Phys. 2016, 55, 04ER02. [CrossRef]

8. Vudumula, P.; Kotamraju, S. Design and Optimization of 1.2-kV SiC Planar Inversion MOSFET Using Split Dummy Gate Concept for High-Frequency Applications. IEEE Trans. Electron Devices 2019, 66, 5266-5271. [CrossRef] 
9. Agarwal, A.K.; Siergiej, R.R.; Seshadri, S.; White, M.H.; McMullin, P.G.; Burk, A.A.; Rowland, L.B.; Brandt, C.D.; Hopkins, R.H. A critical look at the performance advantages and limitations of $4 \mathrm{H}-\mathrm{SiC}$ power UMOSFET structures. In Proceedings of the 8th International Symposium on Power Semiconductor Devices and ICs, Maui, HI, USA, 23 May 1996; pp. 119-122.

10. Singh, R.; Hefner, A.R. Reliability of SiC MOS devices. Solid State Electron. 2004, 48, 1717-1720. [CrossRef]

11. Siemieniec, R.; Peters, D.; Esteve, R.; Bergner, W.; Basler, T.; Zippelius, B.; Kuck, D.; Aichinger, T. A SiC Trench MOSFET concept offering improved channel mobility and high reliability. In Proceedings of the 19th European Conference on Power Electronics and Applications (EPE'17 ECCE Europe), Warsaw, Poland, 11-14 September 2017; pp. P.1-P.13.

12. Kagawa, Y.; Fujiwara, N.; Sugawara, K.; Tanaka, R.; Fukui, Y.; Yamamoto, Y.; Miura, N.; Imaizumi, M.; Nakata, S.; Yamakawa, S. 4H-SiC Trench MOSFET with Bottom Oxide Protection. Mater. Sci. Forum 2014, 778-780, 919-922. [CrossRef]

13. Kobayashi, Y.; Kinoshita, A.; Onishi, Y. Simulation Based Prediction of SiC Trench MOSFET Characteristics. FUJI Elect. Rev. 2016, 62, 12-16.

14. Baliga, B.J. Silicon Carbide Power Devices; World Scientific: Singapore, 2006; pp. 339-358.

15. Li, Y.; Cooper, J.; Capano, M. High-voltage (3 kV) UMOSFETs in 4H-SiC. IEEE Trans. Electron Devices 2002, 49, 972-975. [CrossRef]

16. Yang, T.; Bai, S.; Huang, R. 4H-SiC trench MOSFET with splitting double-stacked shielded region. Superlattices Microstruct. 2018, 122, 419-425. [CrossRef]

17. Wei, J.; Zhang, M.; Jiang, H.; Cheng, C.-H.; Chen, K.J. Low ON-Resistance SiC Trench/Planar MOSFET With Reduced OFF-State Oxide Field and Low Gate Charges. IEEE Electron Device Lett. 2016, 37, 1458-1461. [CrossRef]

18. Jiang, H.; Wei, J.; Dai, X.; Ke, M.; Deviny, I.; Mawby, P. SiC Trench MOSFET With Shielded Fin-Shaped Gate to Reduce Oxide Field and Switching Loss. IEEE Electron Device Lett. 2016, 37, 1324-1327. [CrossRef]

19. Zhou, X.; Yue, R.; Zhang, J.; Dai, G.; Li, J.; Wang, Y. 4H-SiC trench MOSFET with floating/grounded junction barrier-controlled gate structure. IEEE Trans. Electron Devices 2017, 64, 4568-4574. [CrossRef]

20. Peters, D.; Basler, T.; Zippelius, B.; Aichinger, T.; Bergner, W.; Esteve, R.; Kueck, D.; Siemieniec, R. The new CoolSiC ${ }^{\text {TM }}$ Trench MOSFET Technology for Low Gate Oxide Stress and High Performance. In Proceedings of the International Exhibition and Conference for Power Electronics, Intelligent Motion, Renewable Energy and Energy Management, Nuremberg, Germany, 16-18 May 2017; pp. 168-174.

21. Peters, D.; Siemieniec, R.; Aichinger, T.; Basler, T.; Esteve, R.; Bergner, W.; Kueck, D. Performance and ruggedness of $1200 \mathrm{~V}$ SiC Trench MOSFET. In Proceedings of the 29th International Symposium on Power Semiconductor Devices and IC's (ISPSD), Sapporo, Japan, 28 May-1 June 2017; pp. 239-242.

22. Nakamura, T.; Nakano, Y.; Aketa, M.; Mitani, S.; Sakairi, H.; Yokotsuji, Y. High performance SiC trench devices with ultra-low Ron. In Proceedings of the International Electron Devices Meeting, Washington, DC, USA, 5-7 December 2011; pp. 26.5.1-26.5.3.

23. Sampath, M.; Morisette, D.; Cooper, J.A. Comparison of singleand double-trench UMOSFETs in 4H-SiC. In Materials Science Forum; Trans Tech Publications Ltd.: Freienbach, Switzerland, 2018; Volume 924, pp. 752-755.

24. Wei, J.; Liu, S.; Yang, L.; Tang, L.; Lou, R.; Li, T.; Fang, J.; Li, S.; Zhang, C.; Sun, W. Investigations on the Degradations of Double-Trench SiC Power MOSFETs Under Repetitive Avalanche Stress. IEEE Trans. Electron Devices 2018, 66, 546-552. [CrossRef]

25. Kyogoku, S.; Tanaka, K.; Ariyoshi, K.; Iijima, R.; Kobayashi, Y.; Harada, S. Role of Trench Bottom Shielding Region on Switching Characteristics of $4 \mathrm{H}-\mathrm{SiC}$ Double-Trench Mosfets. Mater. Sci. Forum 2018, 924, 748-751. [CrossRef]

26. Kim, T.; Kim, K. High Breakdown Voltage and Low On-Resistance 4H-SiC UMOSFET with Source-Trench Optimization. ECS J. Solid State Sci. Technol. 2019, 8, Q147-Q152. [CrossRef]

27. Kobayashi, Y.; Harada, S.; Ishimori, H.; Takasu, S.; Kojima, T.; Ariyoshi, K.; Sometani, M.; Senzaki, J.; Takei, M.; Tanaka, Y.; et al. 3.3 kV-Class 4H-SiC UMOSFET by Double-Trench with Tilt Angle Ion Implantation. Mater. Sci. Forum 2016, 858, 974-977. [CrossRef]

28. Jiang, J.-Y.; Wu, T.-L.; Zhao, F.; Huang, C.-F. Numerical Study of 4H-SiC UMOSFETs with Split-Gate and P+ Shielding. Energies 2020, 13, 1122. [CrossRef]

29. Saha, A.; Cooper, J.A. A 1-kV 4H-SiC Power DMOSFET Optimized for Low on-Resistance. IEEE Trans. Electron Devices 2007, 54, 2786-2791. [CrossRef] 
30. Synopsys Inc. Sentaurus Device, User Manual, Version O-2018.06; Synopsys Inc.: Mountain View, CA, USA, 2018.

31. Lombardi, C.; Manzini, S.; Saporito, A.; Vanzi, M. A physically based mobility model for numerical simulation of nonplanar devices. IEEE Trans. Comput. Des. Integr. Circuits Syst. 1988, 7, 1164-1171. [CrossRef]

32. Hatakeyama, T.; Nishio, J.; Ota, C.; Shinohe, T. Physical modeling and scaling properties of $4 \mathrm{H}-\mathrm{SiC}$ power devices. In Proceedings of the International Conference On Simulation of Semiconductor Processes and Devices, Tokyo, Japan, 1-3 September 2005; pp. 171-174.

33. Zhao, Y.; Niwa, H.; Kimoto, T. Impact ionization coefficients of $4 \mathrm{H}-\mathrm{SiC}$ in a wide temperature range. Jpn. J. Appl. Phys. 2018, 58, 018001. [CrossRef]

34. Kang, H.; Udrea, F. On the Quasi-Saturation in State-of-the-Art Power MOSFETs. IEEE Electron Device Lett. 2019, 40, 754-756. [CrossRef]

35. Goh, J.; Kim, K. Low on-resistance 4H-SiC UMOSFET with local floating superjunction. J. Comput. Electron. 2019, 19, 234-241. [CrossRef]

36. Dimarino, C.; Chen, Z.; Danilovic, M.; Boroyevich, D.; Burgos, R.; Mattavelli, P. High-temperature characterization and comparison of $1.2 \mathrm{kV} \mathrm{SiC}$ power MOSFETs. In Proceedings of the IEEE Energy Conversion Congress and Exposition, Denver, CO, USA, 15-19 September 2013; pp. 3235-3242. [CrossRef]

37. Baliga, B.J. Fundamentals of Power Semiconductor Devices; Springer: Berlin, Germany, 2008; pp. $279-497$.

38. Wei, J.; Zhang, M.; Jiang, H.; Wang, H.; Chen, K.J. Dynamic Degradation in SiC Trench MOSFET With a Floating p-Shield Revealed with Numerical Simulations. IEEE Trans. Electron Devices 2017, 64, 2592-2598. [CrossRef]

39. Alatise, O.; Parker-Allotey, N.-A.; Jennings, M.; Mawby, P.; Kennedy, I.; Petkos, G. Modeling the Impact of the Trench Depth on the Gate-Drain Capacitance in Power MOSFETs. IEEE Electron Device Lett. 2011, 32, 1269-1271. [CrossRef]

40. Luo, X.; Liao, T.; Wei, J.; Fang, J.; Yang, F.; Zhang, B. A novel 4H-SiC trench MOSFET with double shielding structures and ultralow gate-drain charge. J. Semicond. 2019, 40, 052803. [CrossRef]

41. Han, K.J.; Baliga, B.J.; Sung, W. A Novel 1.2 kV 4H-SiC Buffered-Gate (BG) MOSFET: Analysis and Experimental Results. IEEE Electron Device Lett. 2017, 39, 248-251. [CrossRef]

42. Zhang, J.; Rees, F.L.; Hull, B.; Casady, J.B.; Allen, S.; Palmour, J.W. Impact of next-generation $1700 \mathrm{~V}$ SiC MOSFETs in a 125kW PV converter. In Proceedings of the IEEE Energy Conversion Congress and Exposition (ECCE), Cincinnati, OH, USA, 1-5 October 2017; pp. 911-916.

43. Tian, K.; Hallen, A.; Qi, J.; Ma, S.; Fei, X.; Zhang, A.; Liu, W. An Improved 4H-SiC Trench-Gate MOSFET With Low ON-Resistance and Switching Loss. IEEE Trans. Electron Devices 2019, 66, 2307-2313. [CrossRef]

44. Graovac, D.; Purschel, M.; Kiep, A. MOSFET power losses calculation using the data-sheet parameters application note, v1.1. Infineon Technol. AG 2006, 1, 1-23.

45. Backlund, B.; Schnell, R.; Ulrich, S.; Roland, F. Applying IGBTs; Application Note 5SYA2053-01; ABB: Lenzburg, Switzerland, 2007.

Publisher's Note: MDPI stays neutral with regard to jurisdictional claims in published maps and institutional affiliations.

(C) 2020 by the authors. Licensee MDPI, Basel, Switzerland. This article is an open access article distributed under the terms and conditions of the Creative Commons Attribution (CC BY) license (http://creativecommons.org/licenses/by/4.0/). 